The effect of age on cultural schema: The case of Shekaste-nafsi (modesty) in Persian

Shirinbakhsh, Salva $\llbracket$

University of Isfahan, Iran (salvashirinbakhsh@gmail.com)

Eslami Rasekh, Abbass

University of Isfahan, Iran (abbasseslamirasekh@yahoo.com)

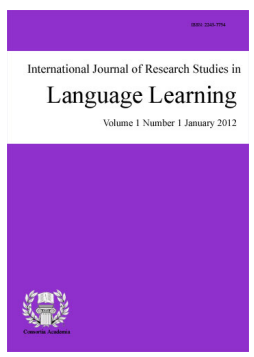

ISSN: $2243-7754$ Online ISSN: 2243-7762

OPEN ACCESS

\title{
Abstract
}

Drawing on the theory of a cultural schema, this work focuses on the effect of age as a social variable on the instantiation of Persian cultural schema referred to as Shekaste-nafsi (modesty) in compliment responses. The schema motivates speakers to evade the compliment by lowering themselves and raising the other. This study seeks to quantitatively and qualitatively examine the pattern of schema activation in Persian cultural setting. The thrust of the study is to see 'how' the schema is practiced in young and old Persian speakers. Data were collected from a corpus of 63 hours of audio-taped conversations analyzed through a conversation analytic (CA) methodology. The results of analysis revealed that age has a significant effect on the distribution and frequency of this schema in the sense that age effect makes the speech of the young fairly similar to the globalized culture of speech and less similar to that of their previous generation. The underlying causes were attributed to globalization and socio-economic status of Iran.

Keywords: culture; schema; compliment; age; Persian 


\section{The effect of age on cultural schema: The case of Shekaste-nafsi (modesty) in Persian}

\section{Introduction}

"Cognition" has been viewed in different aspects throughout its history. In classical view, it was mainly associated with mind and mental activities whereas in connectionist view, cognition emerged from a network of interconnected units called neurons (e.g., Davis, 1992; Plunkett, 1988). In more recent perspective, cognition is viewed as "situated" activity in the society (Greeno \& Moore, 1993). It maintains that knowledge is not an entity but an action determined in the environment. It considers the unique sociocultural situation to which an individual's cognition has been exposed to. That is, the interaction of cognition and environment cannot be separated from the cultural, social and physical contexts (Greeno, 1994). In recent years, scholars have become more interested in the interaction of cognition, culture and language (Anderson, 2003; Bernárdez, 2008; Kristiansen, 2008; Sharifian, 2008b) and they define cognition as "a property of cultural groups and not just individuals" (Sharifian, 2008b, p. 111). They regard cognition collectively across the minds of individuals in a society. The collective cognition is mainly composed of the cognition of each individual which "bears the imprint of the types of social activity an individual can be expected to carry out in the sociocultural group $(s) s / h e$ belongs to" (Bernárdez, 2008, p. 151). Putting it another way, members of a cultural group share their collective cognition or their prior knowledge with other members. This cognition can be instantiated through the abstract patterns gained through experience, called schemas. Schemata might be counted as units of organization in the cognition.

Being defined as "an active organization of past experience" (Bartlett, 1932, p. 201) or "building blocks of cognition" (Rumelhart, 1980), schema functions both as structure and process in analyzing information. Schema is thought to be structure as an abstract pattern; the pattern through which step by step information necessary for a given context is organized at an abstract level. In practical situation, when a person assimilates experiences and events to his schema in order to make sense of it, the schema is considered as a process. In other word, Human's comprehension largely depends on prior knowledge, therefore on their process of their mental schema.

Moreover, cognitive structures required for a successful social interaction in a cultural setting are considered as cultural schemas (Nishida, 1999). Cultural schemas, reflecting cultural group's collective knowledge and thought (Malcolm \& Sharifian, 2002; Rice, 1980) are cultural perceptual and conceptual information which pave the way for individuals to act appropriately in a cultural group and make sense of their cultural environment. Sharifian (2008b) argued that cultural schemas are heterogeneously imprinted in the minds of a cultural group across time and space and emerge in interpersonal interactions. He explained that no one individual has the same proportion of cultural cognition. Therefore, acquisition of just one schema does not guarantee membership of a cultural group since two people can have more of a cultural schema and less of another. "It is the overall degree of how much a person draws on various cultural schemas that makes an individual more or less representative of a cultural group"(Kristiansen, 2008, p. 409).

Regarding the literature, there has been a good effort to explicate some cultural schemas among Persian speakers (Assadi 1980; Beeman 1986; Beeman 1988; Beeman 2001; Koutlaki 2002; Sahragard 2003; Németh 2008) or to compare them with their western or eastern counterpart schemas (Asjodi 2001; Eslami 2005; Sharifian, 2005; Salmani-Nodoushan 2006; Sharifian \& Jamarani, 2011). For example in her article, Koutlaki (2002) described the nature and practice of a famous Persian verbal ritual for politeness called taa'rof in interpersonal communications. In addition, Sahragard (2003) by employing natural semantic metalanguage (NSM) method, explained taa'rof with its subschemas. Asjodi (2001) went further and compared schema of taa'rof with that of limo in Chinese. In a more recent attempt, Sharifian (2005) introduced cultural schema of Shekaste-nafsi in his article on compliment speech act. He compared compliment responses in Anglo-Australian and Persian and concluded that Persian speakers largely practice the schema of Shekaste-nafsi (modesty) in their 
responses while Anglo-Australian speakers do not use a similar schema. In another study (2008a), he was interested in the extent to which Persian speakers draw on their cultural conceptualization, i.e. Shekaste-nafsi in their L1 and L2 (English) in compliment responses. His results revealed that speakers of Persian employ their cultural schemas in varying degrees in their L1 and L2.

Most of these studies, however, were concerned about the nature of schemas, their absence or presence in the community or their comparisons with other cultures. To give a more representative picture of a cultural group, it is better to account approximately, for the ways in which cultural schemas are distributed in a speech community. It is not enough to say if a cultural schema is present in a community or absent in another, rather, it is the 'how' of its distribution which is significant since most intercultural communication misunderstandings are rooted in the 'how' of conceptual structure existence. In other words, the knowledge of 'what' cultural schemas constitute a cultural group does not distinguish one cultural community from others; rather, the degree and extent to which members of that community draw on schemas.

This paper in an attempt to explain cultural schema of Shekaste-nafsi (modesty) in the light of social variables, intends to probe in the distribution of this schema among Persian speakers with different age groups. In addition, since this schema is mostly prominent in the speech act of compliment responses, we explore the instantiation of the schema concerning four compliment topics i.e., skill, character, appearance and possession. Specifically, the study concerns with below research questions:

1. Do participants in different age groups instantiate the schema of Shekaste-nafsi in various degrees in their compliment responses?

2. If yes, how are they different in compliment topics?

The rest examines the notion of Shekaste-nafsi (modesty) which proceeds with methodology of the research. Following is the analysis of the effect of age on the schema and its distribution among Persian speakers in different topics of compliment. Finally, there is conclusion and discussion of the study.

\subsection{Cultural schema of Shekaste-nafsi}

Shekaste-nafsi schema is literally glossed as "self-breaking". It might be roughly close to the concept of 'modesty' in English. The significance of this schema could lie in its frequent instantiations in conversations, especially in compliment responses, as a sign of politeness to evade the compliment which is given in terms of a praise of the addressee's characteristics, possession, appearance or skills. Shekaste-nafsi can be a subcategory to the cultural schema of $A d a b$ (politeness/respect) (Sharifian, 2008a). It seems Adab as a schema does not have a close equivalent word in English; this is evident in the considerable number of meanings introduced by Glasse (1989) in his encyclopedia: 'being courteous, polite, well-bred, making a feast, courtesy, politeness, urbanity, good breeding, respect, reverence, propriety of conduct, discipline, chastisement, morality, sound doctrine, the essence of polite learning'. Each of the translated versions given interprets a part of the schema of Adab. Cultural schema of $A d a b$ encourages the speaker to be a good person, say good words and have good conduct even in the long run (Sahragard, 2003). Put another way, drawing on Adab cultural schema, the speaker makes an attempt to save and enhance the face of addressee verbally.

Since Persian is a language of Adab (politeness/respect), one may draws upon the schema of Shekaste-nafsi to gently evade compliment; so that it does not make the listener feel inferior and also it does not make the speaker feel arrogance. In fact, it is used in line with the policy of "self-lowering other-raising" (Beeman, 2001, p. 41) which is counted as the manifestation of Adab (politeness/respect) in speech among Persians. For instance, in the example below complimentee instantiates the schema to reject the compliment: 
Shirinbakhsh, S. \& Eslami Rasekh, A.

Sample (1)

\section{1}

Dast pokht-e-t

aali-yel.

Hand cook (Noun)-of-you (2nd sing) excellent-is.

'Your cooking is excellent'.

2

Nabaabaa, oon tor-haa ham ni-st. Maal-e khod-e-t behtar-e.

No daddy, that-way-s also not-is possession-of self- of-you (2nd sing) better-is.

'No, it's not like that. Your cooking is better'.

3

Shekaste nafs-i mi-kon-i.

Broken self -i (gerund marker) mi(continuous marker)-do (imperative)- you (2nd sing)

'You're doing Shekaste-nafsi'.

In the first part the compliment is offered; in the second part, speaker two rejects it by denying the good quality of food. The pair continues by speaker two returning the compliment to speaker one. This happens while the interlocutors both are aware of Shekaste-nafsi schema underlying the conversation as it is explicitly mentioned by speaker one in the end. It can be seen that the main concern of this cultural schema is saving the face of addressees while avoiding the speaker to be arrogant or egoistic. This definition of Shekaste-nafsi might bring to mind the notion of 'downgrading' in English. However, there is a very delicate difference between these two. Considering the contexts these two notions are employed, it could be inferred that Shekaste-nafsi is mainly about a person or self while 'downgrading' is used to refer to both a person and status. In literal translation of Shekaste-nafsi the notion of 'self' is prominent. "Breaking-self" might refer to a very old spiritual tradition of a Persian religious group called 'Sufism' in which suppression of egoism is emphasized in order to reach the purification of soul see also (Sharifian, Ahmadi, \& Ahmadi, 1998; 2008a). Therefore, exclusive nature of self in Shekaste-nafsi schema is evident.

In the following section the method employed to gather the data is explained.

\section{Method}

In order to scrutinize the instantiation of Shekaste-nafsi schema in compliment responses, Conversation Analysis (CA) was employed. It seems CA, as an ethnographic method, is well suited for our purpose since Golato (2002, p. 549) argues for its suitability for "the close study of culturally determined speech events since... [by taping]... it allows for the repeated and detail analysis of a phenomenon in its sequential context... since data are always spontaneous, they represent what speakers are actually doing in conversation".

The data were collected from a corpus of 63 hours of audio-taped conversation among friends and families during two months. The speakers had an age range of 13 to 65 with mean number 37 . Overall, the 24 speakers

\footnotetext{
${ }^{1}$ In Persian transcription, 'a' represents the sound in 'bag' and 'aa' represents the sound in 'father'.
} 
uttered 57 compliment sequences. To control the effect of social variables power, distance, gender and age, only those compliment pairs which were uttered among friends with the same power, distance, gender and age group were considered. Data were transcribed and assigned to two different age groups (13-20) and (50-60), i.e., young adults and middle-aged adults. In data transcription of the study, top lines represent the Persian data in italics, the second line is a literal translation and the last line is an English equivalent translation in punctuation marks (" ').

The analysis of the corpus data will present in the next section.

\section{Analysis}

The corpus of compliments and their responses were divided into four categories which represented the four topics of compliments: skill, character, appearance, and possession. Different cases of Shekaste-nafsi instantiations were identified in the young and old groups. The frequency of Shekaste-nafsi schema in response to compliments on the whole and in each group was calculated. General frequency is shown in Table 1:

\section{Table 1}

General frequency pattern of Shekaste-nafsi use

\begin{tabular}{lcc}
\hline & \multicolumn{2}{c}{$\begin{array}{c}\text { Frequency } \\
\text { Middle-aged adults } \%\end{array}$} \\
\hline Shekaste-nafsi schema & 28.7 & 43.6 \\
\hline
\end{tabular}

Apparently the distribution of the schema is more intense among middle-age group than in young one. This result confirms to Sharifian's notion of 'heterogeneously distributed' schemas among people. He (2004, p. 206) maintained that the distribution of schemas "lends itself more to a continuum...rather than 'all or none'... two members may share more of one cultural schema but less of another". Moreover, he counted social variables such as age, gender, education, and many other responsible for the patterns of distribution among speakers of a community.

To examine if the same pattern happens for the different topics of compliment, each topic was analyzed separately in the two age groups. Analysis follows below:

\section{Table 2}

Shekaste-nafsi use regarding skill

\begin{tabular}{lcc}
\hline & \multicolumn{2}{c}{ Skill } \\
& Young adults $\%$ & Middle-aged adults $\%$ \\
\hline Shekaste-nafsi schema & 13.0 & 20.3 \\
\hline
\end{tabular}

Both groups do employ Shekaste-nafsi schema in their evasion of compliment about their skill while young adults instantiate this schema less than older people. There is an example below:

Sample (2)

An 18 year old girl invites her girl friend to a lunch party. When the lunch is almost over, the friend says:

Friend: Vaay che ghazaa-ye khosh-maze-ee bood. Aashpaz-i balad-i haa.

Wow, what food-of happy-tasty-a was. Cooking-i (gerund marker) know you (2nd sing) haa (emphasize marker)

'Wow, what a tasty food it was. You know how to cook.' 
Host: Na baba, oon tor-aa ham balad n-ist-am. Faghat hamin ye no ghazaa ro balad-am khosh-maze be-paz-am.

$\begin{aligned} \text { No, daddy } & \text { that-way-s } & \text { also } & \text { know no-am- I . Just this one type food ro (obj } \\ \text { marker) know-I } & \text { happy-tasty } & & \text { besent marker)-cook-I. }\end{aligned}$

'No, I don't know much. I just know how to cook this food tastefully.'

Friend: $b a b a$

Daddy

na-kon.

'Don't downgrade yourself'.

The friend compliments the good quality of the food cooked by the host; however, the host tries to evade the compliment by doing Shekaste-nafsi: 'oon toraa ham balad nistam' (I don't know much) and she continues saying that this was the only tasty food she knows to cook to complete her Shekaste-nafsi. Nevertheless, in the third part, her friend encourages the host to accept the compliment since in her idea the food quality is really good. The same pattern of compliment and compliment response underlined by Shekaste-nafsi schema was found in the conversation of middle-aged adults. They, however, employed more polite style and instantiate Shekaste-nafsi more than young adults as in the example below:

(3) Two middle-aged women, one about 55 and other about 40, met in a party. The 55 year old started the conversation by complimenting the other woman dress:

W1: in lebaas kheili ghashang-e. Khod-et

dookht-i?

This dress very pretty-is. Self-you (2nd sing)

sewed-you (2nd sing)?

'This is a very beautiful dress. Did you sew it yourself?'

W2: bale.

Yes.

W1: aafarin, che honarmand.

Well done. What artist.

'Well done. What an artist'.

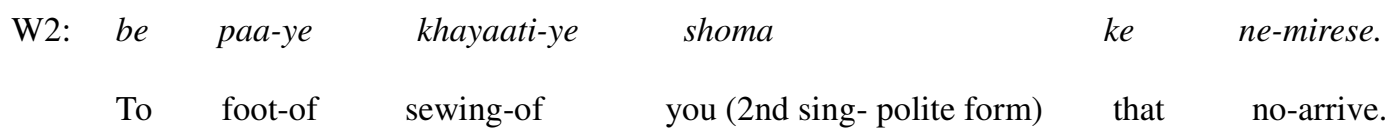

'It's not as skillful as your sewing'.

W1: ekhtiyaar $\quad$ In che harfi-ye.
dige ostaad shod-in, $\quad$ az maazad-injolo.

Will (Noun) have-you (2nd sing- polite form). This what word-is. you (2nd sing- polite form) else professor became (2nd sing- polite form), from we hit (2nd sing- polite form) front. 
'Thanks, but it's not true. You are a professional who has surpassed me'.

Maa dige pir shod-im.

We else old became-we.

'I have become old'.

W2: khaahesh mi-kon-am. Maa shaagerd-e shomaa-eem.

Favor mi (continuous marker)-do-I. We student-of you (2nd sing-polite form)-are.

'You're welcome. I take my hat off to you'.

Table 3

Shekaste-nafsi use regarding character

\begin{tabular}{lcc}
\hline & \multicolumn{3}{c}{ Character } \\
& Young adults $\%$ & Middle-aged adults \% \\
\hline Shekaste-nafsi schema & 8.7 & 13.1 \\
\hline
\end{tabular}

(4) Speaker one has a problem, when she shares her problem with her sister, she tries to soothe her:

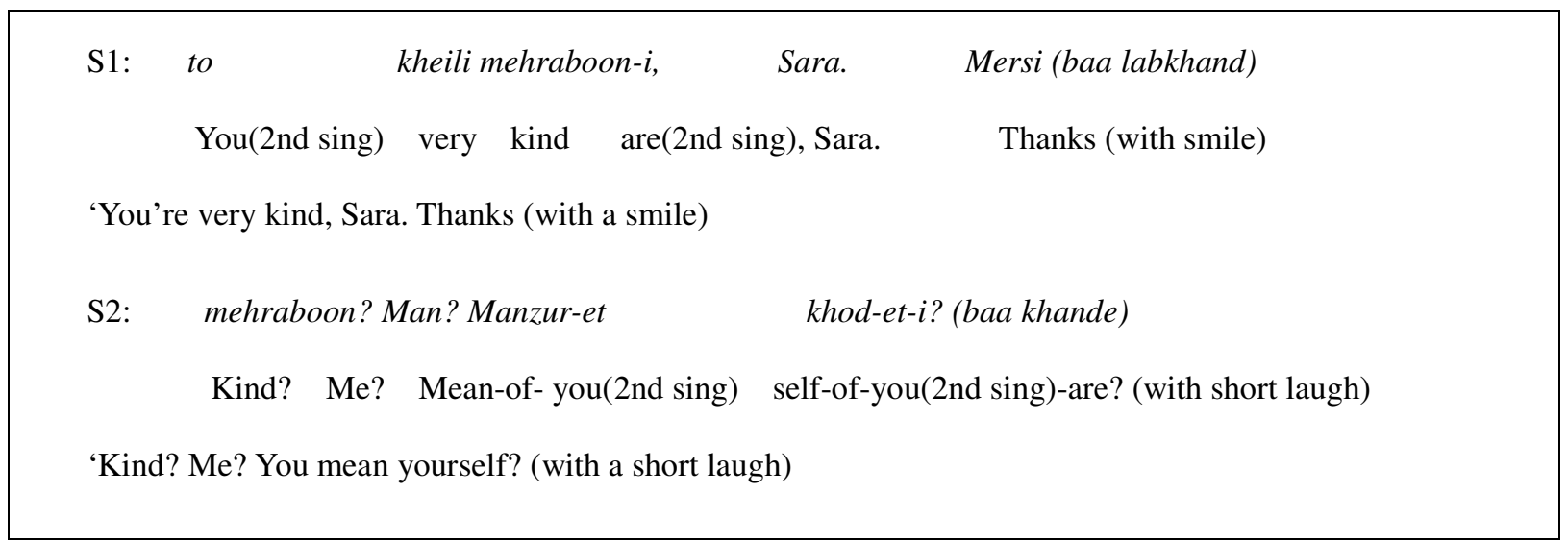

In this example, speaker one compliments her sister's character by admitting that she is very kind. The sister, trying to evade the compliment, draws on Shekaste-nafsi by questioning the adjective and returning it to her sister (last line). This category, also, follows the same trend. Apparently middle-aged adults do Shekaste-nafsi more than their young counterparts when the topic of compliment is about their character.

\section{Table 4}

Shekaste-nafsi use regarding appearance

\begin{tabular}{lcc}
\hline & \multicolumn{2}{c}{ Appearance } \\
& Young adults $\%$ & Middle-aged adults $\%$ \\
\hline Shekaste-nafsi schema & 7.0 & 10.2 \\
\hline
\end{tabular}

It looks that the same trend is followed in this category as well. Young adults' tendency to employ Shekaste-nafsi in their speech about appearance is less than middle-aged adults. This, also, could be due to the fact that most young people are fascinated to look more beautiful and enjoy having compliment in this regard. Thus, it appears that young people are likely to accept compliment regarding their appearance and are reluctant 
Shirinbakhsh, S. \& Eslami Rasekh, A.

to evade or reject it, as in the following example:

(5) There is a wedding party in a family. A 19-year- old boy meets his cousin and says:

\begin{tabular}{|c|c|c|c|}
\hline Boy 1: & khosh-tip & shod-i & emshab \\
\hline & good-look & became-you(2nd sing) & tonight \\
\hline
\end{tabular}

'Dude, you look fantastic tonight'.

Boy 2: man hamishe khosh-tip-am. (baa lab-khand)

I always good-look- am. (with lip-laugh)

'I always am. (with a smile)'.

Boy two playfully answers boy one's compliment. He teases his cousin not to have noticed his being good-looking all the time! In this example, accepting compliment leaves no place for the instantiation of Shekaste-nafsi. This schema is mostly activated in rejection or evasion of compliments. The interesting point is that the category 'appearance' has the lowest percentage of Shekaste-nafsi both in young adults and in middle-aged ones. To demonstrate a case in which middle-aged adults accept compliment - therefore no activation of Shekaste-nafsi happens- the example below is presented:

(6) A friend compliments his friend on his newly cut hair and admits that the hair style suited him. In reply to compliment the friend says:

He: $\quad$ mersi, khod-am-am hes-e khoob-i

Thanks, self-I-also sense-of good-i(gerund marker)

'Thanks, I have a good sense to that, too'.

The practice of Shekaste-nafsi can be detected in a similar case between two middle-aged women in a party:

Sample 7

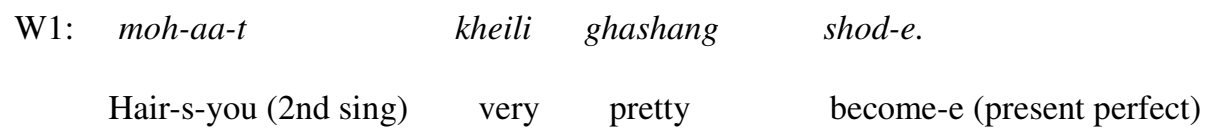

'Your hair is very nice'.

W2: Etefaaghi-ye, in-baar in-tor shod-e.

Accidental-is, this-time this-way become-e (present perfect)

'It's by chance, this time it became like this'

W1: na, to khod-et khoshgel-i hame chi be-het mi-yaad.

No, you(2nd sing) self-of-you pretty-is all thing to-you(2nd sing) mi(continuous marker)-come

'No, you're beautiful so anything suits you.' 


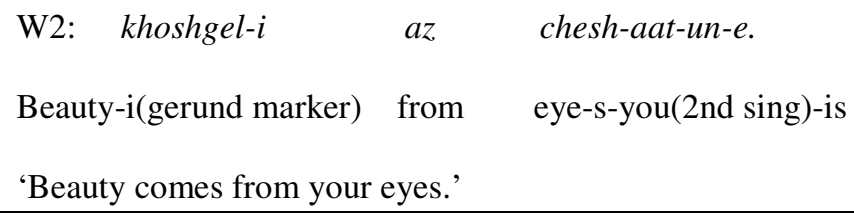

After receiving a compliment, W2 tries to evade the compliment by acknowledging that the nice hair style is accidental i.e. doing Shekaste-nafsi (line two of conversation). W1, however, insists on her being good looking in line three. Finally, W2 returns the compliment and employs Shekaste-nafsiby saying 'Beauty comes from your eyes'. This expression is very common in Persian. By saying 'khoshgeli az cheshaatune' or 'cheshaatun ghashang mibine' (beauty comes from your eyes or your eyes see beautifully) one acknowledges firstly that the object of compliment is not worth much by itself and the value is given by complimenter, and secondly he/she returns the compliment to complimenter. Therefore, two functions are served by saying 'cheshaatun ghashang mibine': Shekaste-nafsi and returning.

\section{Table 5}

Shekaste-nafsi use regarding possession

\begin{tabular}{lcc}
\hline & \multicolumn{3}{c}{ Possession } \\
& Young adults $\%$ & Middle-aged adults $\%$ \\
\hline Shekaste-nafsi schema & 0 & 0 \\
\hline
\end{tabular}

Since Shekaste-nafsi is about self and scaling one's self down, there were no instances of this schema in compliment responses concerning possession. Nevertheless, speakers do downgrade the value of their possessions. The most common expression in this topic was 'ghaabeli nadaare' (it's not worthy of you) which has multiple functions. The usage is presented below:

Sample 8

A: che kif-e ghashang-i.

What bag-of beautiful-a

'What a nice bag!'

B: $\quad$ ghaabel-i na-daar-e.

Worth-a no-has-it.

'It's not worthy of you.'

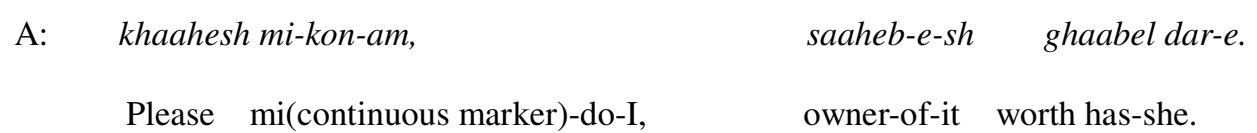

'Please, you are worthy!'

Person A compliments B's bag and B in reply says ghaabeli nadaare (it's not worthy of you). This expression downgrades the value of the object and simultaneously raises the value of complimenter. It means you are so much valuable that this object which is worthless in your presence may be offered to you as a gift. Moreover, this expression is in line with the "self lowering"- "other rising" strategies employed among Iranians 
Shirinbakhsh, S. \& Eslami Rasekh, A.

(Beeman, 2001, p. 41). So, in total the expression ghaabeli nadaare serves three functions of downgrading, other raising and offering the object to complimenter.

\section{Discussion}

Data on the instantiation of Shekaste-nafsi in the four topics of compliments may be depicted as below (young adults - darker shade; middle-aged adults - lighter shade):

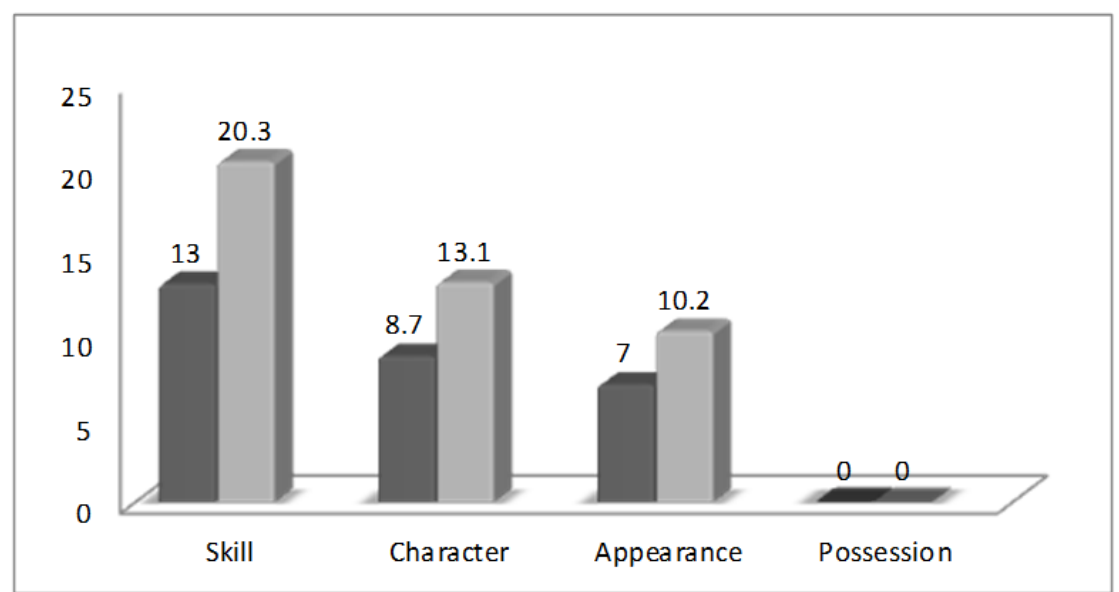

Figure 1. Summary of Shekaste-nafsi use in four topics of compliment

Using compliment in phatic conversation to "oil the social wheel" and "[consolidate] solidarity among people" (Holmes, 1988, p. 462), presents a dilemma for the interlocutors: accepting compliment while avoiding self-praise (Pomerantz, 1978). As Pomerantz (1978, p. 82) stated "recipients of compliments are under the influence of two conflicting constraints which are concurrently relevant but not concurrently satisfiable". The first constraint deals with the fact that preferred reaction toward receiving a positive evaluation in the form of compliment would be an agreement while, simultaneously, according to the second constraint, speakers are to avoid self-praise. It is the constraint which is dictated by their culture. In Persian, schema of Shekaste-nafsi assists speakers in avoiding self-praise; however, the extent to which people make use of this schema seems to be different. As the results revealed, in their evasions of compliment responses, young Persian speakers draw less on Shekaste-nafsi than middle-aged adults.

The fact that young Persians are less keen on employing Shekaste-nafsi in their compliment rejections and are eager to accept compliments could be in line with the transition of Iran traditional society to a modern one, values and cultural schemas are changing as well. The tendency of young Persian speakers to instantiate Shekaste-nafsi, a cultural schema which dates back to the ancient time of Zoroastrian and Sufism in Iran (Sharifian, Ahmadi \& Ahmadi, 1998; 2008a), might be sociologically examined in the light of modern attitudes of Iranian new generation due to the improvement of socio-economic status. According to Inglehart and Baker (2000, p. 42) "rising levels of existential security are the key factor underlying intergenerational value change".

Iran as a developing country, since its Islamic revolution in 1979 has become more industrialized than in its pre-revolutionary era. This shift toward industrialization has brought a variety of changes in people's daily encounters and worldviews (Spier, 1996); higher levels of education and security are two examples. The young group in the study enjoys more security than middle-aged one who spent their youth in the period of Iran revolution. Increase in social security and formal education paved the way for raising autonomous and decision making individuals who tend to be direct as well as self-expressive (Inglehart, 1997). As a result, expression of idea and self, and not 'breaking one's self' has become central for young people in interpersonal relationships. On the other hand, having experienced the insecurity of revolution, adults - in seeking for a strategy of survivalpracticed Shekaste-nafsi or 'breaking their selves' to show their respect to others in their communication. These events "tap an intergenerational shift from an emphasis on economic and physical security toward an increased 
The effect of age on cultural schema: The case of Shekaste-nafsi (modesty) in Persian emphasis on self-expression, subjective well-being and quality-of-life concerns" (Inglehart \& Baker, 2000, p. 26).

Furthermore, the influence of globalization on cultural practices and schemas should not be ignored. Iran, like other developing countries, is dealing with the issue of western culture's invasion into its cultural patterns and thoughts. Global media such as movies, recorded music and internet as the leading edge of globalization (Schlegel, 2001) provide the potential for a gradual change in traditional system of belief and cultural values. Young people might find their cultural schemas and values irrelevant to the new global culture; therefore, there would be a gradual decline in the cultural bindings of young modern individuals, as it was the case in Shekaste-nafsi.

\section{Conclusion}

This study was concerned about the instantiation of cultural schemas specifically Shekaste-nafsi in different age groups in the speech act of compliment in Persian. The results revealed a declining mode of Shekaste-nafsi activation in young group in the four topics of compliment. The study then explored the underlying causes of such decline and youth's modernity attitude. This research is an attempt to add contribution to explicating the patterns of thought in Persian culture and language as well as to intercultural communication.

Through interaction in a cultural setting, a person internalizes a variety of cultural schemas which enable him to behave appropriately in his speech community. However, this set of cultural schemas might debilitate communication across cultures since in every interaction each individual draws on his sources of schemas which possibly are different from that of his counterpart in order to interact and interpret messages. In other words, each person in interaction evaluates and interprets others' behavior and speech by referring to his own cultural cognition. Therefore, developing some knowledge of other cultural schemas i.e. meta-cultural competence (Sharifian, 2005) is a necessity. This enhancement would require not only the familiarity of 'what' cultural schema but also 'how' they are practiced in other cultural settings.

Regarding the limitations, the present study's data were collected by a limited number of participants in a limited scope; during two weeks and among the researchers' friends and families. Moreover, the study was concerned about one social variable in compliment responses i.e. age. Future studies can expand the scope of this paper by including more participants and various social factors as well as different cultural schemas in their research on Persian and other languages. Since Persian, to the best of researchers' knowledge, suffers from lack of attention to its socio-cultural system.

\section{References}

Ahmadi, N., \& Ahmadi, F. (1998). Iranian Islam: The concept of the individual. London: MacMillan. http://dx.doi.org/10.1057/9780230373495

Anderson, M. L. (2003). Embodied cognition: A field guide. Artificial Intelligence, 149(1), 91-130. http://dx.doi.org/10.1016/S0004-3702(03)00054-7

Asjodi, M. (2001). A Comparison between Ta'arof in Persian and Limao in Chinese. International Journal of Sociology of Language, 148, 71-92. http://dx.doi.org/10.1515/ijs1.2001.016

Assadi, R. (1980). Deference: Persian style. Anthropological Linguistics, 22, 221-224.

Bartlett, F. C. (1932). Remembering. Cambridge: Cambridge University Press.

Beeman, W. O. (1986). Language, status, and power in Iran. Bloomington: Indiana University Press.

Beeman, W. O. (1988). Affectivity in Persian language use. Culture, Medicine, and Psychiatry, 12, 9-30. http://dx.doi.org/10.1007/BF00047036

Beeman, W. O. (2001). Emotion and sincerity in Persian discourse: Accomplishing the representation of inner states. International Journal of the Sociology of Language, 148, 31-57. http://dx.doi.org/10.1515/ijsl.2001.013 
Shirinbakhsh, S. \& Eslami Rasekh, A.

Bernárdez, E. (2008). Collective cognition and individual activity: Variation, language and culture. In T. Ziemke, J. Zlatev \& R. M. Frank (Eds.), Body, language and mind (Vol. 2, pp. 137-166). Germany: Mouton de Gruyter.

Davis, S. (1992). Connectionism: Theory and practice. Oxford: Oxford University Press.

Eslami, Z. R. (2005). Invitations in Persian and English: Ostensible or genuine? Intercultural Pragmatics, 2(4), 453-480. http://dx.doi.org/10.1515/iprg.2005.2.4.453

Glasse, C. (1989). The concise encyclopedia of Islam. London: Stacy International.

Golato, A. (2002). German compliment responses. Journal of Pragmatics, 34, 547-571.

Greeno, J. G. (1994). Gibson's affordances. Psychological Review, 101(2), 336-342. http://dx.doi.org/10.1016/S0378-2166(01)00040-6http://dx.doi.org/10.1037/0033-295X.101.2.336

Greeno, J. G., \& Moore, J. L. (1993). Situativity and symbols: Response to Vera and Simon. Cognitive Science, 17(1), 49-59. http://dx.doi.org/10.1207/s15516709 $\operatorname{cog} 1701 \_3$

Holmes, J. (1988). Compliments and compliment responses in New Zealand English. Anthropological Linguistics, 28, 485-508.

Inglehart, R. (1997). Modernization and postmodernization: Cultural, economic, and political change in 43 societies. Princeton, NJ: Princeton University Press.

Inglehart, R., \& Baker, W. E. (2000). Modernization, cultural change, and the persistence of traditional values. American Sociological Review, 65, 19-51. http://dx.doi.org/10.2307/2657288

Koutlaki, S. A. (2002). Offers and expressions of thanks as face enhancing acts: tae'arof in Persian. Journal of Pragmatics, 34(12), 1733-1756. http://dx.doi.org/10.1016/S0378-2166(01)00055-8

Kristiansen, G. (2008). Idealized cultural models: The group as a variable in the development of cognitive schemata. In T. Ziemke, J. Zlatev, \& R. M. Frank (Eds.), Body, language and mind (Vol. 2, pp. 409-432). Germany: Mouton de Gruyter.

Malcolm, I. G., \& Sharifian, F. (2002). Aspects of Aboriginal English oral discourse: An application of cultural schema theory. Discourse Studies, 4(2), 169-181. http://dx.doi.org/10.1177/14614456020040020301

Németh, A. (2008). Ta'ârof as a writer's tool in twentieth century Persian literary prose. Iranian Studies, 41(2), 183-211. http://dx.doi.org/10.1080/00210860801913420

Nishida, H. (1999). A cognitive approach to intercultural communication based on schema theory. International Journal of Intercultural Relations, 23(5), 753-777. http://dx.doi.org/10.1016/S0147-1767(99)00019-X

Plunkett, K. (1988). Parallel distributed processing. Psyke and Logos, 9(2), 307-336.

Pomerantz, A. (1978). Compliment responses: notes on the cooperation of multiple constraints. In J. Schenkein (Ed.), Studies in the organization of conversational interaction (pp. 79-112). New York: Academic Press.

Rice, G. E. (1980). On cultural schemata. American Ethnologist, 7, 152-171. http://dx.doi.org/10.1525/ae.1980.7.1.02a00090

Rumelhart, D. (1980). Schemata: The building blocks of cognition. In R. J. Spiro, B. Bruce, \& W. Brewer (Eds.), Theoretical issues in reading comprehension (pp. 33-58). Hillsdale, NJ: Lawrence Earlbaum.

Sahragard, R. (2003). A cultural script analysis of a politeness feature in Persian. Paper presented at the 8th Pan-Pacific Association of Applied Linguistics, Japan.

Salmani-Nodoushan, M. A. (2006). A comparative sociopragmatic study of ostensible invitations in English and Farsi. Speech Communication, 48, 903-912. http://dx.doi.org/10.1016/j.specom.2005.12.001

Schlegel, A. (2001). The global spread of adolescent culture. In L. J.Crockett \& R. K. Silbereisen (Eds.), Negotiating adolescence in times of social change (pp. 77-88). New York: Cambridge University Press.

Sharifian, F. (2005). The Persian cultural schema of shekasteh-nafsi: A study of complement responses in Persian and Anglo-Australian speakers. Pragmatics and Cognition, 13(2), 337-361. http://dx.doi.org/10.1075/pc.13.2.05sha

Sharifian, F. (2008a). Cultural schemas in L1 and L2 compliment responses: A study of Persian-speaking learners of English. Journal of Politeness Research, 4(1), 55-80.

Sharifian, F. (2008b). Distributed, emergent cultural cognition, conceptualisation, and language. In R. M. Frank, R. Dirven, T. Ziemke, \& E. Bernandez (Eds.), Body, language, and mind (Vol. 2, pp. 109-136). 
Berlin/New York: Mouton de Gruyter.

Sharifian, F., \& Jamarani, M. (2011). Cultural schemas in intercultural communication: A study of the Persian cultural schema of sharmandegi 'being ashamed'. Intercultural Pragmatics, 8(2), 227-251. http://dx.doi.org/10.1515/iprg.2011.011

Sharifian, F., Rochecouste, J., \& Malcolm, I. G. (2004). It was all a bit confusing ...: Comprehending aboriginal English texts. Language, Culture, and Curriculum, 17(3), 203-228. http://dx.doi.org/10.1080/07908310408666694

Spier, F. (1996). The structure of big history: From the big bang until today. Amsterdam, Holland: Amsterdam University Press. 
Shirinbakhsh, S. \& Eslami Rasekh, A. 